\title{
Gender, Competitiveness, and Study Choices in High School: Evidence from Switzerland
}

\author{
By Thomas Buser, Noemi Peter, and Stefan C. Wolter*
}

While women outnumber men on university campuses in most developed countries, strong gender differences in field of study persist. Science, technology, mathematics, and engineering (STEM) related subjects attract relatively few women while the humanities are predominately female. ${ }^{1}{ }^{1}$ In many European countries, specialization into different academic fields begins in high school, and studies show that girls shy away from math-intensive specializations already at that stage. ${ }^{2}$ The choice of a more math-intensive high school specialization has been shown to causally affect labor market earnings (Joensen and Nielsen 2009) and the reluctance of women to pick such specializations is therefore a partial explanation for the gender gap in earnings.

Recent evidence suggests that gender differences in study choices are partially determined by the well-documented gender gap in willingness to compete. ${ }^{3}$ We contribute to this

\footnotetext{
* Buser: University of Amsterdam, PO Box 15867, 1001 NJ Amsterdam, The Netherlands (e-mail: t.buser@uva. nl); Peter: University of Groningen, Faculty of Economics and Business, PO Box 800, 9700AV Groningen, The Netherlands (e-mail: a.n.peter@rug.nl); Wolter: University of Bern, Department of Economics, Schanzeneckstrasse 1, Postfach 8573, 3001 Bern, Switzerland (e-mail: stefan. wolter@vwi.unibe.ch). We gratefully acknowledge funding from the Swiss State Secretariat for Education, Research and Innovation (SERI) through its Leading House on the Economics of Education, Firm Behaviour and Training Policies. The authors thank Rahel Braun, Katharina Jaik, and Michael Raaflaub for their help in collecting and preparing the data and Elif Demiral for her excellent discussion of the paper.

${ }^{\dagger}$ Go to https://doi.org/10.1257/aer.p20171017 to visit the article page for additional materials and author disclosure statement(s).

${ }^{1}$ See, e.g., http://nces.ed.gov/programs/digest/d13/ tables/dt13_322.40.asp and http://nces.ed.gov/programs/ digest/d13/tables/dt13_322.50.asp.

${ }^{2}$ See, e.g., Buser, Niederle, and Oosterbeek (2014) and Joensen and Nielsen (2016).

${ }^{3}$ Niederle and Vesterlund (2011) provide an extensive overview on the gender gap in willingness to compete.
}

literature by examining whether Swiss students' Baccalaureate school (high school) specialization choices can be predicted by an experimental measure of willingness to compete that was elicited more than one-and-a-half years before the specialization choices were made. The aim of Baccalaureate schools is to prepare students for university and students are asked to choose a specialization at the beginning. While girls outnumber boys in Baccalaureate schools,,${ }_{\square}^{4}$ boys are more likely to specialize in math.

Willingness to compete is typically measured by giving individuals a choice between piecerate and competitive incentives for their performance in a simple task in a laboratory setting (Niederle and Vesterlund 2007). A small but growing literature shows that this competition decision is a predictor of study choices and labor market outcomes outside of the lab. Closest to our study is Buser, Niederle, and Oosterbeek (2014) who look at high school students in the Netherlands, and find that competitiveness predicts the choice of more math-heavy specializations in high school. They also find that the gender gap in competitiveness can partially account for the gender differences in specializations. Further studies link competitiveness to the starting salary and industry choice of MBA students (Reuben, Sapienza, and Zingales 2015), to actual and expected labor market earnings (Buser, Geijtenbeek, and Plug 2015; Reuben, Wiswall, and Zafar 2015), to participation in a competitive high school entry exam (Zhang 2013), and to investment choices of entrepreneurs (Berge et al. 2015).

Our findings are in line with the previous literature. We show that conditional on grades and performance in the experiment, students who compete are significantly more likely to choose

\footnotetext{
${ }^{4}$ Boys are more likely to opt for vocational education within the Swiss apprenticeship system.
} 
a math-intensive specialization more than oneand-a-half years later in Swiss academic high schools (Baccalaureate schools). Boys are more likely to compete and this gender difference in competitiveness can explain a significant portion of the gender difference in specialization choices. We also show that the conclusions stay the same after controlling for socioeconomic characteristics.

\section{Background and Data Collection}

In this section, we will first give relevant details on the Swiss education system and then explain the data collection process.

\section{A. Education in Switzerland}

Compulsory schooling in Switzerland consists of six years of primary school followed by three years of lower-secondary school. ${ }^{5}$ After the ninth grade, students can proceed to upper-secondary education. Most students either opt for vocational education within the Swiss apprenticeship system or for Baccalaureate school, an academic high school which prepares students for university. Admission to Baccalaureate schools is selective and depends on grades in lower-secondary school (in some instances entry tests are also required). In the canton of Bern, where we collected our data, about 1 in 5 students continue on to Baccalaureate school.

At the start of their upper-secondary education, Baccalaureate school students have to choose one of the following specializations: physics and math; biology and chemistry; economics and law; ancient languages; modern languages; music and arts; ${ }^{6}$ and philosophy, pedagogy, and psychology. As we will show, this choice is strongly gendered. Physics and math and economics and law are the most popular choices for boys while girls tend toward music and arts, languages, or philosophy, pedagogy, and psychology (see, also, Cantonal Office for Upper-Secondary and Vocational Education of the Canton of Bern 2009).

\footnotetext{
${ }^{5}$ Recently the attendance of two years of preschool also became obligatory. In Switzerland the cantons have authority over the school system, so a few cantons divide the years among the stages slightly differently.

${ }^{6}$ Music and arts are actually separate specializations but because of their similarities we group them together.
}

These gender differences foreshadow striking gender differences in the choice of major at Swiss universities. While women make up around three quarters of students in languages, literature, and social sciences, they make up only one-tenth of students in engineering, one-quarter in exact sciences, and one-third in economics and business (Federal Statistical Office 2011).

\section{B. Data Collection}

In 2013 we experimentally measured the willingness to compete of students at the beginning of eighth grade. The experiment was part of a larger project which collected data from 1,514 students from 28 schools in the canton of Bern. 7 We managed to resurvey more than 95 percent of the students in 2015, at the end of ninth grade, and ask them about their educational and labor market choices and expectations. In this paper we look at specializations in academic high schools and hence we examine the 259 students who chose to continue their studies at a Baccalaureate school..$^{8}$

Our measure of willingness to compete follows Niederle and Vesterlund (2007). The experiment consisted of three rounds, one of which was randomly selected for payment. In each round, participants perform one of two simple tasks: adding up sets of four two-digit numbers or counting the number of times a certain letter appears in a random sequence of 50 letters. Participants had three minutes per round to do as many of these problems as possible and the task type (summation or counting) was randomized across classrooms. The experiment was conducted on computers.

In the first round, participants are paid according to a piece rate of 25 cents per correct answer. In the second round, participants are in competition with three other randomly selected

\footnotetext{
${ }^{7}$ To implement the data collection, all lower-secondary schools were contacted in the German-speaking part of the canton of Bern. To give an incentive for schools to participate, money was paid not only to the students but also into the class funds. In particular, into each class fund we paid the sum of the individual amounts that the students in that class earned. Twenty-eight schools (approximately 10\%) wanted to take part in the data collection. The survey was administered during class hours.

${ }^{8}$ In a companion paper, we will concentrate on the relation between competitiveness and vocational career choices in the Swiss apprenticeship system.
} 
anonymous participants. If they outperform all three participants, they earn SFr 1 per correct answer. If they lose, they receive nothing. In the third round, participants can choose which of the two incentive schemes they prefer. This choice is our measure of willingness to compete.?

After the experiment, students answered a detailed questionnaire, which was also part of the larger data collection project. The survey included questions on students' grades, socioeconomic background, preferences (e.g., risk), and future plans. ${ }^{10}$ Our data on the specialization choices comes from the second data collection that took place in 2015.

\section{Analysis}

In this section, we will first present descriptive statistics of the educational and experimental choices of the students and then examine whether their experimental choices predict their later choice of specialization.

\section{A. Descriptive Statistics}

Our sample consists of 259 students who plan to continue their education at a Baccalaureate school. Of these, we have to drop 10 students who did not state a clear choice of specialization in the questionnaire. As in the canton as a whole, girls are overrepresented in our sample of Baccalaureate school students (the sample consists of 159 girls and 90 boys).

Figure 1 shows the proportions of boys and girls who pick each of the seven specializations. Physics and math is the only one which requires taking more math classes. It attracts 27 percent of boys and 7 percent of girls $(p=0.00$, chi-squared test). As a further illustration of

\footnotetext{
${ }^{9}$ The performance of those who compete is compared to a new random set of performances from the same round. Students were informed about their absolute performance after every round but no relative feedback was given during the experiment.

${ }^{10}$ The risk preference question was incentivized. In particular, the question that we use here asks participants to make a single incentivized choice between a sure payment of SFr 2 and four 50/50 lotteries of increasing variance and expected payoff: 3.50 or $1.50,4$ or 1,5 or $0.50,6$ or 0 (Eckel and Grossman 2002). As the survey was part of a larger data collection effort, it also contained questions on other variables, such as time preferences, locus of control, and sunk cost aversion. The locus of control measure from this data collection is used in Jaik and Wolter (2016).
}

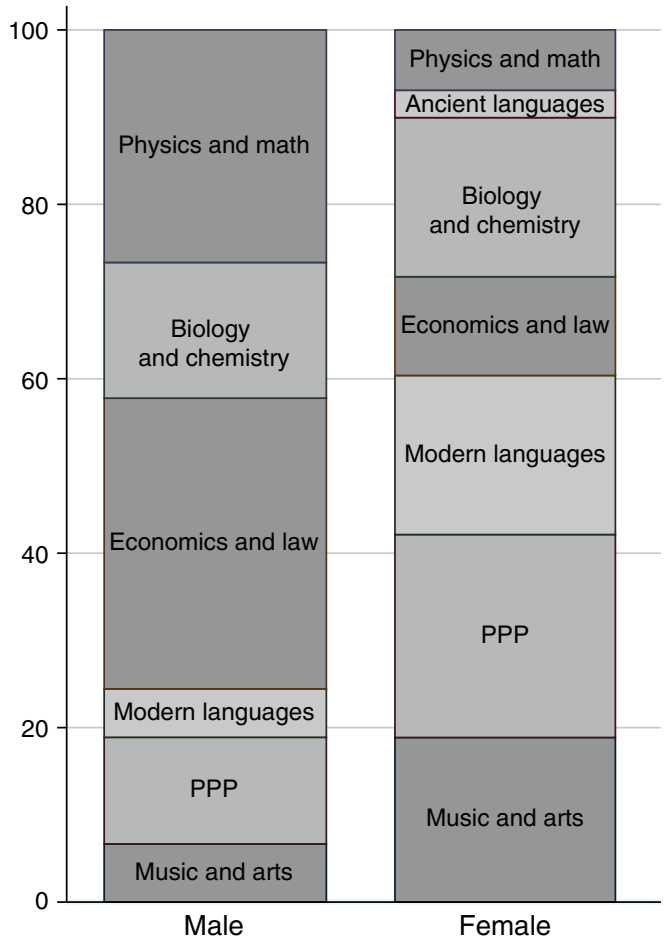

Figure 1. Share of Chosen Specialization by Gender

Note: PPP means philosophy, pedagogy, and psychology.

the gender differences in specialization choice, consider that 76 percent of boys but only 36 percent of girls pick either physics and math, biology and chemistry, or economics and law $(p=0.00)$.

Sixty-eight percent of boys and 51 percent of girls chose to compete in the experiment, a difference of 17 percentage points $(p=0.01)$. Conditional on performance in rounds 1 and 2 and task type, this difference is 20 percentage points $(p=0.00) \cdot{ }^{11}$

\section{B. Regression Analyses}

In this section, we will regress students' specialization choices on gender and a competition dummy to determine whether competitiveness

\footnotetext{
${ }^{11}$ From an OLS regression of a dummy for choosing the competitive option on the number of points scored in rounds 1 and 2, a task dummy, and interactions of task and points scored.
} 
predicts the choice of more math-intensive specializations and whether the gender gap in competitiveness can partially explain the gender differences in specialization choice.

We will run two regression analyses. First, we will look at the binary choice between physics and math and the other specializations. Second, we will use a measure of the chosen specializations' math intensity as an outcome variable, to see whether competitiveness predicts the choice of more math-intensive specializations beyond a dummy-specification. To get an objective approximation of the specializations' level of math intensity, we use the so-called "EVAMAR" math scores. EVAMAR was a research project commissioned by the Swiss Conference of Cantonal Ministers of Education to evaluate the Baccalaureate school reform of 1995 which introduced the specializations that we examine in this paper. ${ }^{12}$ In Phase II of this project, students were tested at the end of Baccalaureate school in several subjects, among them in math. This resulted in the following average math scores by specialization: physics and math: 614 , ancient languages: 512, biology and chemistry: 504, economics and law: 485, modern languages: 475 , philosophy, pedagogy, and psychology: 462, music and arts: 460 (see, Eberle et al. 2008). ${ }^{13}$ We use these EVAMAR scores as our outcome variable in panel B of Table 1 .

Panel A of Table 1 shows the results for choosing physics and math. Conditional on grades and school fixed effects, girls are 16 percentage points less likely to choose this specialization, a large difference considering only 14 percent of students make this choice (column 3 ). In column 4 , we add the binary competition variable. Students who choose to compete are 12 percentage points more likely to specialize in physics and math. Controlling for competitiveness

\footnotetext{
${ }^{12}$ The reform had several other elements as well, see Eberle et al. (2008) for further details on this and on the EVAMAR project.

${ }^{13}$ While only physics and math contains additional, more advanced math, some specializations contain additional math related courses such as chemistry or economics. The second-placed ancient languages seems to be the odd-one out. However, this specialization requires learning Latin and Ancient Greek and is seen as a highly demanding option that is chosen by very few students. In our sample it is chosen by only five students (all female) and eliminating these observations or grouping them with modern languages does not change the results.
}

reduces the gender difference by 17 percent (compare columns 3 and 4). Conditional on risk attitudes and socioeconomic controls, competitiveness increases the likelihood of choosing physics and math by 11 percentage points and explains 14 percent of the gender difference (columns 7 and 8).

In panel B, we use the EVAMAR math score of the chosen specialization as our outcome variable. The results again show that girls choose less math-intensive specializations and competitive students pick more math-intensive specializations. Conditional on grades and school fixed effects, competitiveness reduces the gender gap by 14 percent. If we control for socioeconomic variables as well, this reduction is 11 percent.

\section{Concluding Remarks}

Women are strongly underrepresented in math-intensive fields in most developed countries. This gender difference in study choices is of great policy relevance because it contributes to the gender-earnings gap and because many countries are faced with a shortage of STEM graduates. By linking incentivized measures of competitiveness to real-life career choices, a small but growing literature demonstrates that gender differences in willingness to compete can be a partial explanation for gender differences in career choices, including course choices in high school.

We add to this literature by showing that a binary choice between piece-rate and competitive payment in an experiment is a significant predictor of choosing a math-intensive specialization more than one-and-a-half years later in academic high schools in Switzerland. The size of the competitiveness coefficient is remarkable. In particular, when we look at the choice of specializing in math and physics, it is almost as large in magnitude as the gender coefficient.

We also find that controlling for competitiveness can explain between 9 and 17 percent of the gender difference in study choices. Given that our binary competitiveness measure surely misses a lot of individual variation in preferences for competition, this is probably a lower bound.

\section{REFERENCES}

- Berge, Lars Ivar Oppedal, Kjetil Bjorvatn, Armando Jose Garcia Pires, and Bertil Tungodden. 2015. "Competitive in the Lab, 
Table 1 - Choice of Specialization, Gender, and Competitiveness

\begin{tabular}{|c|c|c|c|c|c|c|c|c|}
\hline & (1) & $(2)$ & (3) & $(4)$ & $(5)$ & $(6)$ & (7) & $(8)$ \\
\hline \multicolumn{9}{|c|}{ Panel A. Choosing physics and math $(O L S)$} \\
\hline Female & $\begin{array}{r}-0.216 \\
(0.050)\end{array}$ & $\begin{array}{r}-0.195 \\
(0.049)\end{array}$ & $\begin{array}{r}-0.156 \\
(0.059)\end{array}$ & $\begin{array}{r}-0.130 \\
(0.057)\end{array}$ & $\begin{array}{r}-0.138 \\
(0.056)\end{array}$ & $\begin{array}{r}-0.117 \\
(0.054)\end{array}$ & $\begin{array}{r}-0.134 \\
(0.055)\end{array}$ & $\begin{array}{r}-0.115 \\
(0.053)\end{array}$ \\
\hline Compete & & $\begin{array}{c}0.108 \\
(0.036)\end{array}$ & & $\begin{array}{c}0.115 \\
(0.044)\end{array}$ & & $\begin{array}{c}0.112 \\
(0.047)\end{array}$ & & $\begin{array}{c}0.107 \\
(0.050)\end{array}$ \\
\hline Reduction in female coefficient & \multicolumn{2}{|c|}{10.0 percent } & \multicolumn{2}{|c|}{16.5 percent } & \multicolumn{2}{|c|}{15.3 percent } & \multicolumn{2}{|c|}{14.3 percent } \\
\hline$p$-value for reduction & \multicolumn{2}{|c|}{0.001} & \multicolumn{2}{|c|}{0.004} & \multicolumn{2}{|c|}{0.006} & \multicolumn{2}{|c|}{0.014} \\
\hline \multicolumn{9}{|c|}{ Panel B. EVAMAR math score of the chosen specialization $(O L S)$} \\
\hline Female & $\begin{array}{r}-33.077 \\
(6.444)\end{array}$ & $\begin{array}{r}-30.165 \\
(6.356)\end{array}$ & $\begin{array}{r}-24.626 \\
(7.348)\end{array}$ & $\begin{array}{r}-21.179 \\
(7.355)\end{array}$ & $\begin{array}{r}-22.291 \\
(7.029)\end{array}$ & $\begin{array}{r}-19.519 \\
(7.032)\end{array}$ & $\begin{array}{r}-22.205 \\
(6.915)\end{array}$ & $\begin{array}{r}-19.692 \\
(6.897)\end{array}$ \\
\hline Compete & & $\begin{array}{c}14.446 \\
(5.114)\end{array}$ & & $\begin{array}{l}15.435 \\
(6.517)\end{array}$ & & $\begin{array}{l}14.646 \\
(6.982)\end{array}$ & & $\begin{array}{l}14.035 \\
(7.339)\end{array}$ \\
\hline Reduction in female coefficient & \multicolumn{2}{|c|}{8.8 percent } & \multicolumn{2}{|c|}{14.0 percent } & \multicolumn{2}{|c|}{12.4 percent } & \multicolumn{2}{|c|}{11.3 percent } \\
\hline$p$-value for reduction & \multicolumn{2}{|c|}{0.003} & \multicolumn{2}{|c|}{0.005} & \multicolumn{2}{|c|}{0.010} & \multicolumn{2}{|c|}{0.020} \\
\hline Task and performance & $\mathrm{x}$ & $\mathrm{x}$ & $\mathrm{x}$ & $\mathrm{x}$ & $\mathrm{x}$ & $\mathrm{x}$ & $\mathrm{x}$ & $\mathrm{x}$ \\
\hline Grades and school fixed effects & & & $\mathrm{x}$ & $\mathrm{x}$ & $\mathrm{x}$ & $\mathrm{x}$ & $\mathrm{x}$ & $\mathrm{x}$ \\
\hline Risk attitudes & & & & & $\mathrm{x}$ & $\mathrm{x}$ & $\mathrm{x}$ & $\mathrm{x}$ \\
\hline Socioeconomic controls & & & & & & & $\mathrm{x}$ & $\mathrm{x}$ \\
\hline Observations & 249 & 249 & 249 & 249 & 249 & 249 & 249 & 249 \\
\hline
\end{tabular}

Notes: Panel A: the outcome variable is a binary indicator for choosing the physics and math specialization. Panel B: the outcome variable is the average EVAMAR math score in the chosen specialization. Compete is a binary indicator for choosing the competitive payment scheme in the experiment; Task and performance means a dummy for task (summation or counting), number of points scored in round 1 and round 2 and interactions; Grades and school fixed effects means math grade and GPA in eighth grade, level of lower-secondary school (elite track or not) and interactions, plus dummies for the attended lower-secondary school; Risk attitudes means dummies for the chosen lottery; and socioeconomic controls includes age in months, dummies for number of siblings, dummies for whether mother and father attended university, and dummies for whether father and mother were born abroad. The $p$-values for the reduction in the female coefficient upon controlling for the competition dummy are bootstrapped (10.000 repetitions, stratified by gender and school; $p$-value is equal to the number of repetitions in which the reduction is negative divided by 10.000). Standard errors in parentheses are clustered at the classroom level.

Successful in the Field?" Journal of Economic Behavior and Organization 118: 303-17.

Buser, Thomas, Lydia Geijtenbeek, and Erik Plug. 2015. "Do Gays Shy Away from Competition? Do Lesbians Compete Too Much?" Institute of the Study of Labor (IZA) Discussion Paper 9382.

- Buser, Thomas, Muriel Niederle, and Hessel Oosterbeek. 2014. "Gender, Competitiveness, and Career Choices." Quarterly Journal of Economics 129 (3): 1409-47.

Cantonal Office for Upper-Secondary and Vocational Education of the Canton of Bern. 2009. Mittelschulbericht 2009-Tradition und Innovation: Das Gymnasium im Kanton Bern: Eine Analyse mit Handlungsempfehlungen.

Eberle, Franz, Karin Gehrer, Beat Jaggi, Johannes Kottonau, Maren Oepke, Michael Pflüger, Christina Huber, Vera Husfeldt, Lukas
Lehmann, and Carsten Quesel. 2008. Evaluation der Maturitätsreform 1995 (EVAMAR): Schlussbericht zur Phase II. Bern: State Secretariat for Education, Research, and Innovation.

-Eckel, Catherine C., and Philip J. Grossman. 2002. "Sex Differences and Statistical Stereotyping in Attitudes toward Financial Risk." Evolution and Human Behavior 23 (4): 281-95.

Federal Statistical Office. 2011. Frauen und Männer an den Schweizer Hochschulen: Indikatoren zu geschlechtsspezifischen Unterschieden. Neuchâtel: Bundesamt Für Statistik.

Jaik, Katharina, and Stefan C. Wolter. 2016. "Lost in Transition: The Influence of Locus of Control on Delaying Educational Decisions." Institute of the Study of Labor (IZA) Discussion Paper 10191.

Joensen, Juanna Schroter, and Helena Skyt 
Nielsen. 2009. "Is There a Causal Effect of High School Math on Labor Market Outcomes?" Journal of Human Resources 44 (1): 171-98.

-Joensen, Juanna Schroter, and Helena Skyt Nielsen. 2016. "Mathematics and Gender: Heterogeneity in Causes and Consequences." Economic Journal 126 (593): 1129-63.

- Niederle, Muriel, and Lise Vesterlund. 2007. "Do Women Shy Away from Competition? Do Men Compete Too Much?" Quarterly Journal of Economics 122 (3): 1067-1101.

- Niederle, Muriel, and Lise Vesterlund. 2011. "Gender and Competition." Annual Review of Economics 3 (1): 601-30.
Reuben, Ernesto, Paola Sapienza, and Luigi Zingales. 2015. "Taste for Competition and the Gender Gap Among Young Business Professionals." National Bureau of Economic Research Working Paper 21695.

Reuben, Ernesto, Matthew Wiswall, and Basit Zafar. 2015. "Preferences and Biases in Educational Choices and Labour Market Expectations: Shrinking the Black Box of Gender." Economic Journal. doi: 10.1111/ecoj.12350.

Zhang, Y. Jane. 2013. "Can Experimental Economics Explain Competitive Behavior Outside the Lab?" https://papers.ssrn.com/sol3/papers. cfm?abstract_id=2292929 (accessed December 19, 2016). 